\section{DISCUSSION}

The concept of pumpless lung assistance depends on a new generation of oxygenator systems with a low transmembrane pressure gradient to remove total body $\mathrm{CO}_{2}$ production and are designed to operate without the help of an external pump. Simply connected to the patient's systemic circulation, they receive only part of the cardiac output for extracorporeal gas exchange. Therefore, stable hemodynamics and the absence of severe peripheral occlusive disease are prerequisites for pECLA implementation. Whereas ample experience has been published applying pECLA as an auxiliary ventilation device in patients with ventilation-refractory lung failure and hypercapnia, only limited data are published applying pECLA as a substitute for ventilation in patients with a normal lung function. ${ }^{5}$ In the presented case, pECLA was applied to ease tracheoesophageal reconstruction by avoiding interferences by the management and handling of the anesthesia tubing.

The applied iLA device is easy to implement and to monitor, so it can be operated by the anesthetist collateral to the usual anesthesiologic equipment. Therefore, this technology is also applicable in small thoracic surgery units that do not have available trained perfusionists. Additionally, no costs are incurred for acquisition and servicing of pump heads.
It has been shown clinically and experimentally that the short iLA tubing lines hardly induce any systemic inflammatory reaction, which may makes these systems applicable for the intraoperative support of tumor patients. ${ }^{5}$

This is, to our best knowledge, the first successful intraoperative application of a pECLA device. Although anecdotal, this encouraging experience unlocks the door for the clinical application of pECLA devices in surgical patients who need exceptionally delicate intraoperative airway management or who need intrathoracic surgery following extensive pulmonary resection where therapeutic interventions are limited.

\section{References}

1. Alfille P. Anesthesia for tracheal surgery. In: Grillo HC, ed. Surgery of the trachea and bronchi Chapter 18. 1st ed. Hamilton, London: BC Decker Inc; 2004: 453-70.

2. Hess DR, Gillette MA. Tracheal gas insufflation and related techniques to introduce gas flow into the trachea. Respir Care. 2001;46:119-29.

3. Matheis G. New technologies for respiratory assist. Perfusion. 2003;18: 245-51.

4. Macchiarini P, Walles T, Biancosino C, Mertsching H. First human transplantation of a bioengineered airway tissue. J Thorac Cardiovasc Surg. 2004;128: 638-41.

5. Walles T. Clinical experience with the iLA membrane ventilator pumpless extracorporeal lung-assist device. Expert Rev Med Devices. 2007;4:297-305.

\title{
Giant left atrial thrombus with mechanical compromise of the mitral valve
}

Andres Beiras-Fernandez, MD, ${ }^{\mathrm{a}}$ Patrick Moehnle, MD, ${ }^{\mathrm{b}}$ Ingo Kaczmarek, MD, ${ }^{\mathrm{a}}$ Florian Weis, MD, ${ }^{\mathrm{b}}$ Bruno Reichart, MD, ${ }^{\mathrm{a}}$ and Calin Vicol, MD, ${ }^{a}$ Munich, Germany

Free-floating giant thrombus is a rare and severe finding observed occasionally in patients with atrial fibrillation and concomitant mitral valve disease. ${ }^{1}$ Herein, we report the case of a 76-year-old woman with acute heart failure and lung edema resulting from a giant left atrial thrombus that mechanically compromised the mitral valve.

\footnotetext{
From the Departments of Cardiac Surgery ${ }^{\mathrm{a}}$ and Anesthesiology, ${ }^{\mathrm{b}}$ Grosshadern University Hospital, Munich, Germany.

Received for publication Nov 4, 2007; revisions received Dec 20, 2007; accepted for publication Dec 22, 2007.

Address for reprints: Andres Beiras-Fernandez, MD, Department of Cardiac Surgery, Grosshadern University Hospital, Marchioninistrasse 15, 81377 Munich, Germany (E-mail: abeiras@med.uni-muenchen.de).

J Thorac Cardiovasc Surg 2008;136:1374-6

$0022-5223 / \$ 34.00$

Copyright (c) 2008 by The American Association for Thoracic Surgery doi:10.1016/j.jtcvs.2007.12.072
}

\section{CLINICAL SUMMARY}

A 76-year-old woman with a record of mitral stenosis was referred to our department because of acute respiratory insufficiency and cardiogenic shock. The electrocardiogram showed atrial fibrillation. Chest radiograph showed massive pulmonary edema and an enlarged heart silhouette. Multislice computed heart tomography showed the presence of intracavitary masses in the enlarged left atrium and confirmed the absence of coronary disease (Figure 1, $A$ and $B$ ).

Transesophageal echocardiography showed a dilated left atrium $(95 \times 80 \mathrm{~mm})$ and severe mitral valve insufficiency, as well as confirming the presence of two thrombi. The larger one was an $80 \times 65-\mathrm{mm}$ free-floating ball thrombus in the middle of left atrium (Figure 2, A) and the second 

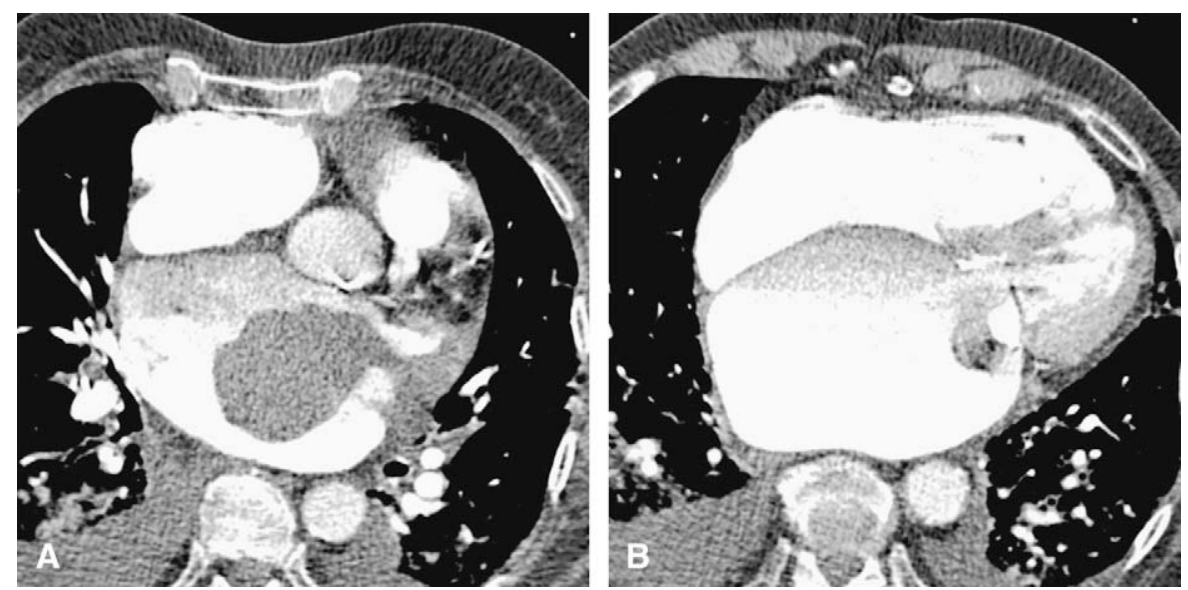

FIGURE 1. Computed tomographic study of thorax showed an enlarged left atrium containing a giant thrombus $(70 \times 60 \mathrm{~mm})$ attached to the lateral wall (A), as well as a second one $(35 \times 30 \mathrm{~mm})$ compromising the mitral valve $(\mathrm{B})$.

one had a hooklike form $(40 \times 20 \mathrm{~mm}$; Figure $2, B)$, which caused intermittent occlusion of the mitral valve and penetrated in the left ventricle.

The patient immediately underwent cardiopulmonary bypass surgery. The left atrium was opened and both thrombi were dissected, removed, and sent for pathologic examination, which revealed chronic thrombus formation. The mitral valve was severely damaged and had to be replaced with a biological prosthesis (Mosaic $29 \mathrm{~mm}$; Medtronic $\mathrm{GmbH}$, Duesseldorf, Germany). The patient was uneventfully weaned off cardiopulmonary bypass. The postoperative period presented no complications and the patient was discharged receiving anticoagulation therapy with phenprocoumon after 10 days. Histopathologic evaluation revealed macroscopically a massive thrombus $(70 \times$ $60 \times 50 \mathrm{~mm}$ ) formed on the left atrial free wall, probably because of impaired atrial flow in the setting of a pre-existing mitral valve stenosis and persistent atrial fibrillation (Figure $2, C)$. A second thrombus $(35 \times 35 \times 7 \mathrm{~mm})$ with a hooklike form was formed on the basis of the first one and penetrated through the mitral valve in the left ventricle (Figure 2, $C$ ).

\section{DISCUSSION}

Mitral valve disease, especially mitral valve stenosis and atrial fibrillation, are factors leading to formation of intra-atrial thrombi. Free-floating thrombi are occasionally seen and may lead to embolic complications. ${ }^{1}$ Transesophageal echocardiography has been recommended as the best diagnostic tool for the detection of left atrial thrombi and also for guiding further therapy designed to reduce the thromboembolic risk. ${ }^{2}$ Furthermore, multislice computed heart tomography not only provides information about the coronary status of the patient but also allows evaluating the compromise of the mitral valve. Mechanical obstruction of the mitral valve without preliminary symptoms is a rare and severe complication. ${ }^{3}$
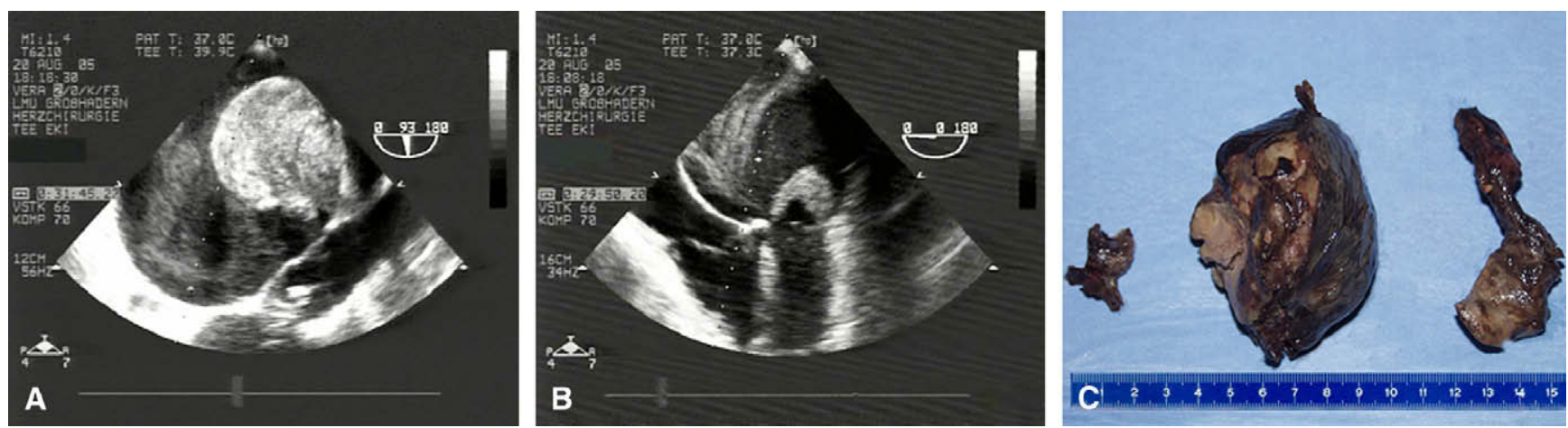

FIGURE 2. Transesophageal echocardiography revealed a giant ball thrombus attached to the free left atrium wall (A). Another thrombus was highly mobile and prolapsed through the damaged mitral valve into the left ventricle (B). Macroscopically, a massive ball thrombus $(70 \times 60 \times 50 \mathrm{~mm}$; $\mathrm{C})$ and a second thrombus $(35 \times 35 \times 7 \mathrm{~mm}$; $)$ with a hooklike form could be observed after surgical resection. 
However, it should be suspected in patients with cardiogenic shock and pulmonary edema in the presence of atrial fibrillation and mitral valve disease, especially mitral stenosis. In our patient, previous mitral stenosis was aggravated by a thrombus penetrating the left ventricle, which caused mechanical mitral insufficiency. Surgical removal of the thrombi with simultaneous treatment of the underlying cause, in this case replacement of the mitral valve, and subsequent anticoagulation is the therapy of choice. ${ }^{4,5}$

\section{References}

1. Noji Y, Kojima T, Aoyama T, Yamaguchi M, Araki T, Fujino S, et al. Free-floating thrombus in right heart and massive pulmonary embolism migrating into pulmonary artery. Circulation. 2005;111:e438-9.

2. Leung D, Davidson P, Cranney G, Walsh W. Thromboembolic risks of left atrial thrombus detected by transesophageal echocardiogram. Am J Cardiol. 1997;79: 626-9.

3. Tornoczky T, Ajtay Z. Images in clinical medicine. Fatal free-floating left atrial thrombus. NEJM. 2004;351:e25.

4. Tsioufis CP, Stefanadis CI, Tsiamis EG, Kallikazaros IE, Toutouzas PK. A free floating ball thrombus in the left atrial cavity. J Thorac Cardiovasc Surg. 1999;118:1120-2.

5. Grandmougin D, Letourneau T, Favre JP, Barral X. Paroxysmal postural dyspnea related to a left atrial ball thrombus. Ann Thorac Surg. 2002;74:1691-4.

\title{
Patients with truncus arteriosus do not have a patent arterial duct: True or false?
}

\author{
Luca A. Vricella, MD, FACS, and Duke E. Cameron, MD, Baltimore, Md
}

It is commonly believed that in the absence of aortic arch interruption, ${ }^{1}$ neonates given diagnoses of truncus arteriosus (or common arterial trunk [CAT]) should not have coexistence of a patent ductus arteriosus (PDA). Simultaneous presence of a PDA and CAT has been reported with extreme rarity. ${ }^{2}$ Figure 1 shows an intraoperative photograph taken during the complete repair of a $3.4-\mathrm{kg}$ newborn with type II CAT (Collett and Edwards classification ${ }^{3}$ ). The right and left branch pulmonary arteries are retracted on snares, and between their respective origins from the arterial trunk, a PDA is seen joining the pulmonary arterial confluence and the uninterrupted aortic isthmus.

In the 1976 classic article describing clinical, angiocardiographic, and pathologic findings in 100 patients with CAT, ${ }^{3}$ a PDA was observed in 14 patients. Among these, aortic arch interruption and anomalous ductal origin of the pulmonary artery were present in 10 and 2 patients, respectively. A PDA was well documented in only $2 \%$ of patients without the above-mentioned associated anomalies.

\section{References}

1. Konstantinov IE, Karamlou T, Blackstone EH, Mosca RS, Lofland GK, Caldarone CA, et al. Truncus arteriosus associated with interrupted aortic arch in 50 neonates: a Congenital Heart Surgeons Society Study. Ann Thorac Surg. 2006;81:214-23.

From the Division of Cardiac Surgery, The Johns Hopkins Medical Institutions, Baltimore, Md.

Received for publication Nov 3, 2007; accepted for publication Dec 16, 2007.

Address for reprints: Luca A. Vricella, MD, FACS, Division of Cardiac Surgery, The Johns Hopkins Hospital, $600 \mathrm{~N}$ Wolfe St-Blalock 618, Baltimore, MD, 21287 (E-mail: lvricella@jhmi.edu).

J Thorac Cardiovasc Surg 2008;136:1376

$0022-5223 / \$ 34.00$

Copyright (c) 2008 by The American Association for Thoracic Surgery doi:10.1016/j.jtcvs.2007.12.048

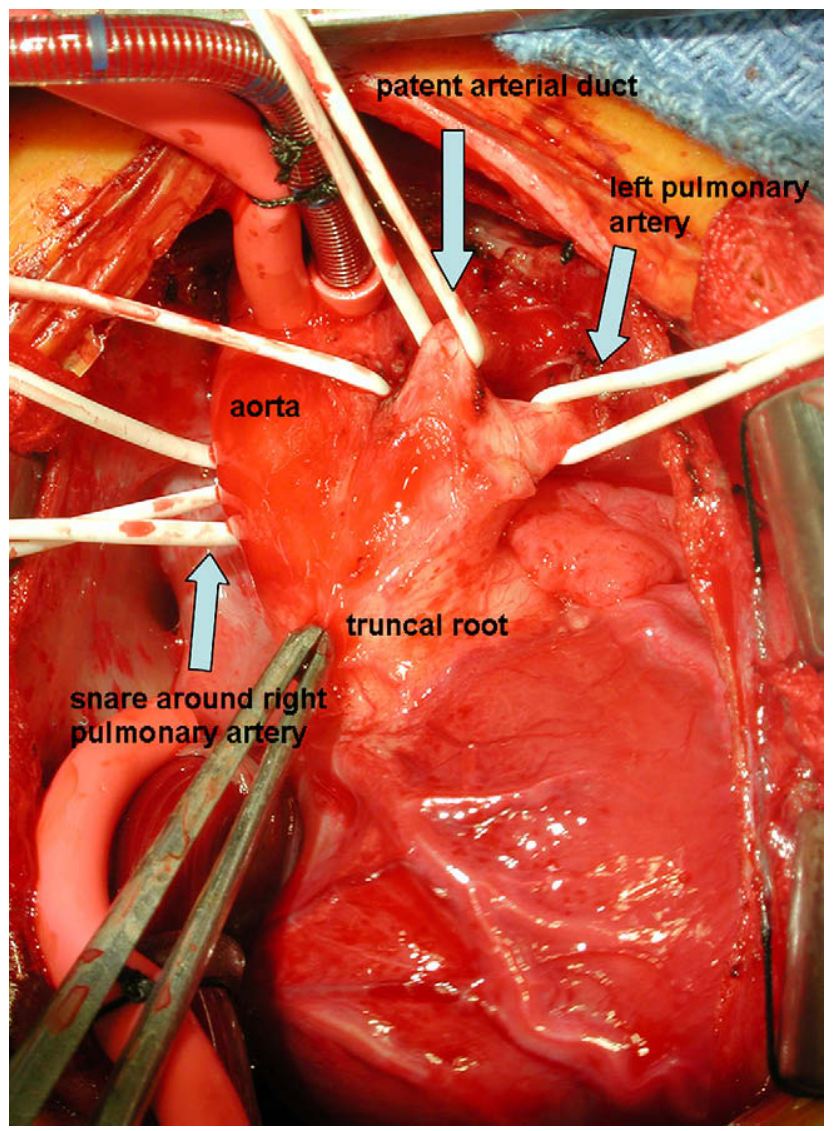

FIGURE 1. Intraoperative photograph of a newborn with type II CAT.

2. Collett RW, Edwards JE. Persistent truncus arteriosus; a classification according to anatomic types. Surg Clin North Am. 1949;29:1245-69.

3. Calder L, Van Praagh RV, Van Praagh S, Sears WP, Corwin R, Levy A, et al. Clinical, angiocardiographic, and pathologic findings in 100 patients. Am Heart J. 1976;92:23-38. 